\title{
Publisher Correction: Maritime Continent water cycle regulates low-latitude chokepoint of global ocean circulation
}

\author{
Tong Lee (iD ${ }^{1}$, Séverine Fournier ${ }^{1}$, Arnold L. Gordon (iD ${ }^{2}$ \& Janet Sprintall ${ }^{3}$
}

Correction to: Nature Communications https://doi.org/10.1038/s41467-019-10109-z, published online 08 May 2019.

The original version of this Article contained errors in Figs. 7 and 8 in which the $y$-axes labels were omitted. In Fig. 7, the y-axes labels on both panels now read 'SSS tendency (pss/month)'. In Fig. 8, the y-axes labels on both panels now read 'Horizontal advective tendency (pss/month)'.

In the original version of Fig. 10, the title incorrectly read 'Meridional SSS profile along Makassar Strait'. The correct version replaces 'SSS' with 'SLA'.

Finally, the second sentence of the fourth paragraph of the 'Data' section of the Methods originally incorrectly read 'The product is available through https://podaac.jpl.nasa.gov/dataset/OSTIA-UKMO-L4-GLOB-v2.0.' The correct version replaced the web link with 'https://www.catds.fr/Products/Available-products-from-CEC-OS/CEC-Locean-L3-Debiased-v3'.

This has been corrected in both the PDF and HTML versions of the Article.

Published online: 21 June 2019

\footnotetext{
(c) Open Access This article is licensed under a Creative Commons Attribution 4.0 International License, which permits use, sharing, adaptation, distribution and reproduction in any medium or format, as long as you give appropriate credit to the original author(s) and the source, provide a link to the Creative Commons license, and indicate if changes were made. The images or other third party material in this article are included in the article's Creative Commons license, unless indicated otherwise in a credit line to the material. If material is not included in the article's Creative Commons license and your intended use is not permitted by statutory regulation or exceeds the permitted use, you will need to obtain permission directly from the copyright holder. To view a copy of this license, visit http://creativecommons.org/licenses/by/4.0/.
}

(c) The Author(s) 2019

\footnotetext{
${ }^{1}$ Jet Propulsion Laboratory, California Institute of Technology, Pasadena, CA 91011, USA. ${ }^{2}$ Lamont-Doherty Earth Observatory, Columbia University, Palisades, NY 10964, USA. ${ }^{3}$ Scripps Institution of Oceanography, University of California, San Diego, CA 92037, USA. Correspondence and requests for materials should be addressed to T.L. (email: tlee@jpl.nasa.gov)
} 